\title{
Microvascular Decompression using Muscle Graft for Vertebral Artery Medullary Compression Syndrome
}

\author{
Prasanna Karki $P h D^{1}$, Damber Bikram Shah $M S^{2}$, Sumit Joshi $M S^{3}$, Prakash Paudel $F C P S^{4}$, Jessica \\ Kayastha $M B B S^{5}$, Gopal Raman Sharma $M S^{6}$ \\ 1,2,3,4,5,6 Department of Neurosciences, Nepal Mediciti, Sainbu, Lalitpur, Nepal
}

Date of submission: $9^{\text {th }}$ September 2020

Date of acceptance: $30^{\text {th }}$ October 2020

Date of publication: $1^{\text {st }}$ December 2020

\section{Abstract}

It is well known that brainstem dysfunction may be caused by vascular compression of the medulla oblongata. However, only a limited number of reports have found microvascular decompression surgery to be an effective treatment for symptomatic patients with medulla oblongata dysfunction.

This report describes a patient with vertebral artery compression of lateral medulla oblongata who presented with lateral medullary syndrome. Microvascular decompression surgery using the transcondylar fossa approach was effective in relieving patient symptoms.

The transcondylar fossa approach and the transposition of vertebral artery along with autologous muscle graft interposition technique is appropriate in microvascular decompression surgery to relieve vertebral artery compression of medulla oblongata.

Key words: Lateral medullary syndrome, Microvascular decompression, Muscle graft

\section{Introduction}

$\mathrm{M}$ edullary compression syndrome (MCS) is a rare manifestation and rarer is it caused by abnormal

Access this article online
Website: https://www.nepjol.info/index.php/NJN
DOI: https://doi.org/10.3126/njn.v17i3.33128
HOW TO CITE
Karki P, Shah DB, Joshi S, Paudel P, Kayastha J, Sharma GR.
Microvascular Decompression using Muscle Graft for Vertebral
Artery Medullary Compression Syndrome. NJNS. 2020;17(3):55-
$\mathbf{5 8}$

'ORCID id: 0000-0003-1469-3517

2ORCID id: 0000-0002-5707-7696

${ }^{3}$ ORCID id: 0000-0002-7883-9354

${ }^{4}$ ORCID id: 0000-0002-8830-3908

${ }^{5}$ ORCID id: 0000-0001-6107-7325

${ }^{6}$ ORCID id: 0000-0003-3638-4993

\author{
Address for correspondence: \\ Dr. Prasanna Karki \\ Nepal Mediciti, \\ Bhaisepati, Lalitpur, Nepal \\ E-mail: prasannakarki7@gmail.com \\ Phone: +9779851227377
}

Copyright (C) 2020 Nepalese Society of Neurosurgeons (NESON)

ISSN: 1813-1948 (Print), 1813-1956 (Online)

This work is licensed under a Creative Commons Attribution-Non Commercial 4.0 International License. ectatic blood vessels. ${ }^{1,2}$ Some known causes of MCS are tumors arising in the region of skull base, congenital and acquired bony abnormalities of cranio-cervical region. Microvascular decompression (MVD) surgery is a highly effective and safe treatment to relieve syndromes of cranial nerve dysfunction. ${ }^{3,4}$ The symptoms vary depending upon the site of compression. Here we report a case of medullary compression by dolichoectatic vertebral artery presenting with symptoms of lateral medullary syndrome. MVD surgery was done to relieve medulla oblongata compression. We discuss the effectiveness and indication of MVD surgery in MCS.

\section{Case Report}

A 57-year-old woman was admitted to our hospital with complaints of difficulty walking, hemisensory disturbances on the left side of body, headache and dizziness. At the time of admission, the patient had ataxic gait, horizontal nystagmus, mild weakness of right upper and lower limbs (Medical Research Council grade 4/5), paresthesia of the left side of body. Medulla Oblongata compression by the dominant and tortuous left Vertebral Artery (VA) was confirmed by magnetic resonance imaging (MRI) (Figure $1 \mathrm{~A}$ and $1 \mathrm{~B}$ ); therefore, we suspected that her symptoms were a result of Lateral Medullary Syndrome (LMS). We performed MVD surgery through the left transcondylar fossa approach. The motor and somatosensory evoked potentials were monitored intraoperatively. The patient was placed in the lateral position and the head held in 


\section{Karki et al}

three-point pin fixation with the neck slightly flexed, the vertex angled slightly down, and the face rotated slightly ventrally, so that the ipsilateral external auditory meatus and the mastoid bone were at the highest point. A retroauricular curvilinear skin incision started approximately 2 to $3 \mathrm{~cm}$ behind the ear and continued inferiorly into the neck over the posterior border of the sternocleidomastoid muscle to cervical C-3 or C-4 level. Suboccipital craniotomy with asymmetric removal of the posterior arch of $\mathrm{C} 1$ was performed. After cutting the dura to reflect it towards the sinus, cisterna magna was opened followed by opening of the cerebellopontine cistern. The V4 segment of the left VA was exposed and, after stepwise microsurgical dissection of arachnoid band adhesions in between VA and MO, the arterial loop compressing the medulla was reached. The VA was observed to strongly compress the MO (Figure 1C). The VA loop was dissected and shifted away carefully from the brainstem so as to not harm the lower cranial nerves, followed by placement of the separating material (muscle in our case) between the medulla and the VA. After visual verification of proper brainstem decompression, we used $1 \mathrm{~cm} \times 1 \mathrm{~cm} \times 5 \mathrm{~cm}$ autologous muscle graft as an interposition material for decompression (Figure 1D). The patient was symptom free after surgery and discharged on the tenth day of surgery.
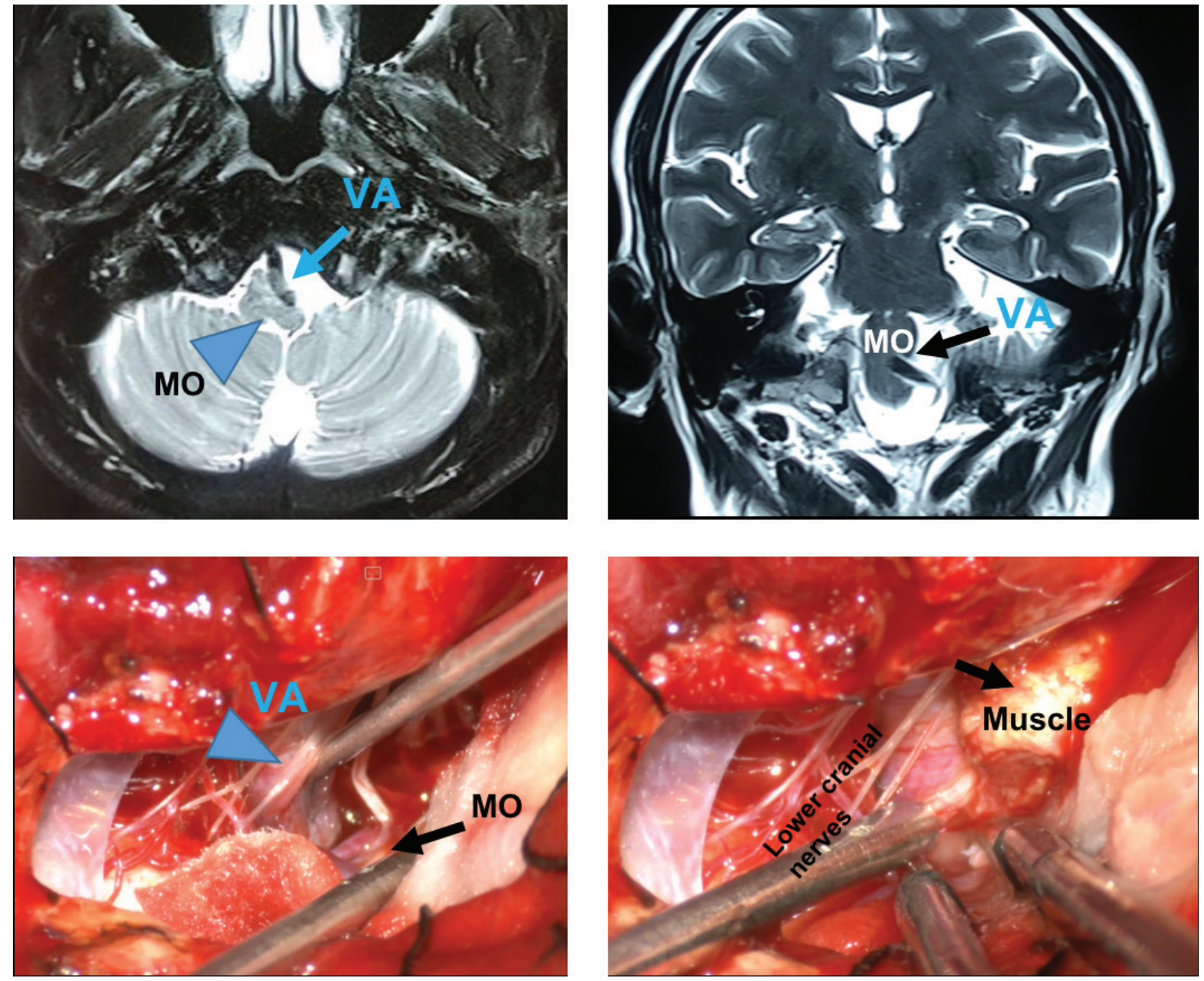

Figure 1: (A) MRI T2W image axial and (B) coronal showing the deep indentation of the vertebral artery (arrow) into the medulla (arrowhead). (C) Intra operative pictures- vertebral artery (VA) (arrowhead) in the region of cerebellomedullary fissure compressing medulla oblangata (MO) (arrow). (D) The VA is lifted off the medulla and autologous muscle graft (arrow) was placed. 


\section{Microvascular Decompression for Vertebral Artery Medullary Compression Syndrome}

\section{Discussion}

In the current report, we have described a case of hemiparesis caused by compression of the medulla oblongata by an ectatic and tortuous vertebral artery. Hemiparesis of the patient was markedly attenuated with successful MVD surgery. In our case vertebral dolichoectasia may be the cause of ischemic symptoms that result from turbulent blood flow and atherosclerosis as well as compression symptoms. A considerable impact of pulsatile compression on the medulla may be confirmed by the exacerbation of preexisting symptoms, which were observed following physical effort as reported in other reports. ${ }^{1}$

To the best of our knowledge, less than 35 cases of surgically treated vertebral artery medullary compression syndrome has been reported so far. ${ }^{1}$ Kim et al. reported the first case of a symptomatic conflict of the vertebral artery and the medulla in a patient who presented with hemiparesis and hypoglossal nerve paresis. ${ }^{2}$ Depending on the level of the medulla compression by the VA with regard to the decussation of pyramids, vertebral artery medullary compression syndrome may be associated with ipsilateral or contralateral hemiparesis. ${ }^{3,4,5}$ Furthermore, the outermost nerve fibers innervate the lower extremities, which may be associated with an earlier occurrence of motor deficit in the lower extremities. ${ }^{2}$ In our case, the first symptom was paresthesia of left side body followed by motor weakness of right upper and lower limbs which is a sign that the long tracts were being compressed. The compression of lateral medulla and medial medulla leads to paresis of upper and lower extremities respectively. Whereas rostral ventrolateral medulla has role in mediating the central pressure response. Therefore, the symptoms of patients with MCS can vary according to the site of compression over medulla by ectatic vertebral artery. Our case had normal vital signs throughout her stay, with hemiparesis which correlates with the compression site. ${ }^{6}$

Various surgical techniques are postulated in previous reports for medullary compression syndrome, i.e. MVD by interposition with autologous or vascular prosthesis between VA and medulla, MVD by transposition with anchoring (Teflon sling, clips, suturing) and VA section. Uncommonly Gore-tex vascular grafts are also being used as separating material. ${ }^{7}$ Some have reported the use of a sling technique to tether the vertebrobasilar artery with the help of clips to the clival dura for macrovascular decompression. $^{8,9}$ Rare case of hypersomnia caused by compression of medulla by dolicoectatic VA which was benefited by microvascular decompression surgery (MVD) by using a synthetic Teflon patch as an interposing material. ${ }^{10}$ The use of autologous muscle graft in our case is cost-effective when compared to Teflon and has least possibility of recurrence due to adhesion unlike with other synthetic materials as reported before. ${ }^{11}$ In this case, the transcondylar approach was used due to our familiarity with this route whereas to apply sling directed towards clivus after transposition of VA needs far lateral approach which is not done in our case. ${ }^{8}$

There is no specific treatment protocol for MCS but till date MVD is the best treatment option to relieve the compression symptoms with good symptomatic improvement. When the artery involved is a dolichoectatic vertebrobasilar artery, the usual procedure is technically more difficult and has to be adapted. Thus, this type of compression is definitively technically more complex than compression by other vessels. Our patient showed marked improvement after MVD surgery. Electrophysiologic monitoring was undertaken intraoperatively, and it has the advantage of ensuring the safety of adjacent cranial nerves, thus greatly increasing the feasibility and safety of MVD surgery.

\section{Conclusion}

As the symptoms of medullary compression can be vague and mislead the diagnosis, sufficient evaluation should be carried out to determine a differential diagnosis, thus, to identify a potential cause. MVD surgery with intraoperative nerve monitoring relieves vascular compression and improves patient symptoms.

\section{Conflict of Interest: None}

Source(s) of support: None

\section{References}

1. Ejma M, Koszewicz M, Podemski R, Marianska K, Budrewicz S, Turek T. Anatomical variation of the vertebral artery clinically mimicking myasthenia gravis. Neurol Sci. 2011;32(4):715-7. https://doi. org/10.1186/s43163-020-00010-8

2. Kim P, Ishijima $B$, Takahashi H, Shimizu H, Yokochi M. Hemiparesis caused by vertebral artery compression of the medulla oblongata: case report. J Neurosurg. 1985;62(3):425-9. https://doi. org/10.3171/jns.1985.62.3.0425.

3. Hongo K, Nakagawa H, Morota N, Isobe M. Vascular compression of the medulla oblongata by the vertebral artery: report of two cases. Neurosurgery. 1999;45(4):907. https://doi.org/10.1097/00006123199910000-00039.

4. Tomasello F, Alafaci C, Salpietro FM, Longo M. Bulbar compression by an ectatic vertebral 


\section{Karki et al}

artery: a novel neurovascular construct relieved by microsurgical decompression. Operat Neurosurg. 2005;56(1):117-24. https://doi.org/10.1227/01 . neu.0000146684.23593.b4.

5. Sadashiva N, Shukla D, Bhat DI, Devi BI. Vertebral artery dolicoectasia with brainstem compression: role of microvascular decompression in relieving pyramidal weakness. Acta Neurochir (Wien). 2016;158(4):797-801. https://doi.org/10.1007/ s00701-016-2715-6.

6. Ren J, Sun H, Diao Y, et al. Successful Treatment with Microvascular Decompression Surgery of a Patient with Hemiparesis Caused by Vertebral Artery Compression of the Medulla Oblongata: Case Report and Review of the Literature. World Neurosurg. 2017;108:994.e11-994.e19. https://doi.org/10.1016/j. wneu.2017.09.016

7. Ubogu EE, Chase CM, Verrees MA, Metzger AK, Zaidat OO. Cervicomedullary junction compression caused by vertebral artery dolichoectasia and requiring surgical treatment. Case report. J Neurosurg. 2002;96(1):140-3. https://doi.org/10.3171/
8. Choudhri O, Connolly ID, Lawton MT. Macrovascular decompression of the brainstem and cranial nerves: evolution of an anteromedial vertebrobasilar artery transposition technique. Neurosurgery. 2017;81:36776. https://doi.org/10.1093/neuros/nyx110

9. Lin $\mathrm{CF}$, Chen $\mathrm{HH}$, Hernesniemi J, Lee CC, Liao $\mathrm{CH}$, Chen SC, et al. An easy adjustable method of ectatic vertebrobasilar artery trans- position for microvascular decompression. Clin Neurol Neurosurg. 2012;114:951-6. https://doi.org/10.1016/j. clineuro.2012.02.021

10. Ghorbani M, Azar M, Bavand K, Shojaei H, Mollahoseini R. Successful microvascular decompression surgery for dolichoectatic vertebral artery compression of medulla oblongata in a patient with hypersomnia disorder [published online ahead of print, 2019 Apr 24]. Br J Neurosurg. 2019;1-3. https://doi.org/10.1080/02688697.2019.1594694

11. Hassan H, Marion M, Michael C, Arnaud D, Pierre LJ. Endoscopy-assisted microvascular decompression for trigeminal neuralgia: the prognostic impact of interposing material. J Int Adv Otol. 2014;10:107-12. https://doi.org/10.1016/j.wneu.2016.06.097 